\title{
A Study on Eco-Tourism and Sustainable Development of Economic Underdevelopment Areas-An Example from Kanas Nature Reserve, Xingjiang Province, Northwest China
}

\author{
Jianxiong Qin', Pei Zhang1, Guiping Deng'2, Lu Chen ${ }^{3}$ \\ ${ }^{1}$ College of Tourism Historical Culture, Southwest University for Nationalities, Chengdu, China \\ ${ }^{2}$ Science Department, Jiuzhaigou National Nature Reserve Administration, Jiuzhai, China \\ ${ }^{3}$ Institude of Geographic Sciences and Natural Resources Research, CAS, Beijing, China \\ Email: jx-qin@vip.163.com, 283428785@qq.com, gdeng@umich.edu, chenlu@igsnrr.ac.cn
}

Received 9 April 2014; revised 20 May 2014; accepted 2 June 2014

Copyright (C) 2014 by authors and Scientific Research Publishing Inc.

This work is licensed under the Creative Commons Attribution International License (CC BY).

http://creativecommons.org/licenses/by/4.0/

(c) (i) Open Access

\begin{abstract}
Based on the assessment of eco-tourism resource and its location advantage, the paper has discussed the principle, projects, and facilities of eco-tourism, in the Kanas Nature Reserve in Xinjiang as well as the direction of related industries. To solve the problems occurred at present in the Kanas Nature Reserve, strategic counter measures of sustainable development of eco-tourism have also been put forward, including: 1) The establishment of eco-tourism planning legislative system of eco-tourism; 2) The establishment of environmental protection planning system of ecotourism; 3) The establishment of environmental audit system of eco-tourism; 4) The establishment environmental legislation and law enforcement system of eco-tourism; 5) The establishment ethic education and management system of eco-tourism.
\end{abstract}

Keywords

Resources Characteristics, Eco-Tourism, Sustainable Development, Economic Underdeveloped Areas

\section{Introduction}

Kanas National Nature Reserve is located at the west side of Aletai Mountain and the north banks of Burqin

How to cite this paper: Qin, J.X., Zhang, P., Deng, G.P. and Chen, L. (2014) A Study on Eco-Tourism and Sustainable Development of Economic Underdevelopment Areas-An Example from Kanas Nature Reserve, Xingjiang Province, Northwest China. Smart Grid and Renewable Energy, 5, 170-179. http://dx.doi.org/10.4236/sgre.2014.57016 
River and Geba River. It borders on Kazakhstan and Russia in the northwest. Kanas Lake is its center. Kanas National Nature Reserve is $66 \mathrm{~km}$ in length from south to north and $74 \mathrm{~km}$ in width from west to east with an area of about 250,000 hectares, accounting to around $23.72 \%$ of Burqin's total area. It mainly protects the natural landscapes including the cold temperate zone mixed coniferous and broad-leaved forests eco-system and the alpine lake Kanas (Figure 1).

Kanas enjoys advantageous geographical position and natural condition. Its biological combination is also extraordinary. The Taiga forest in this area is the only southern Siberia zone of flora and fauna in China, especially the Xinjiang five-leaved pine and fir can only be found here. Thus Kanas is of great value for nature protection and scientific research. Here it can be seen that the forests alternate with the grassland. The communities keep their original state. It has clear vegetation vertical band and the contemporary glaciers are well preserved. Therefore, Kanas possesses unique eco-system and beautiful natural scenery. Many kinds of flowers, trees, birds and animals in this zone are unique in Xinjiang and even whole China. It is also the only area where the Tuvans live in a compact community.

As a high level tourism pattern demonstrating the concept of sustainable development [1]-[4], eco-tourism's core objective is to promote the coordination between natural resources protection and local economic development [5]-[7]. Developing eco-tourism in Kanas Nature Reserve not only provides new opportunities for the construction and development of the nature reserve, but also is of vital significance in driving local economic development, enhancing the public's awareness to protect the nature and expanding the social influence of the nature reserve.

\section{The Characteristics of the Resources and the Comment}

\subsection{The Characteristics of the Eco-Tourism Resources}

1) Lake landscape. The Kanas lake surface is $1374 \mathrm{~m}$ in altitude. The lake is $24 \mathrm{~km}$ in length from south to north and its widest part reaches $9 \mathrm{~km}$ from west to east. The depth of the lake is at most $188.5 \mathrm{~m}$ and its area is $45 \mathrm{~km}^{2}$. Kanas Lake is the deepest alpine freshwater lake in China. Its characteristic landscapes include lake view, discoloration lake, water monster, sea of clouds and glory of the Buddha. The towering snow mountains all around, green slopes and thick forests, gorgeous flowers and colorful butterflies and the natural beauty of lakes and mountains present a fantastic view.

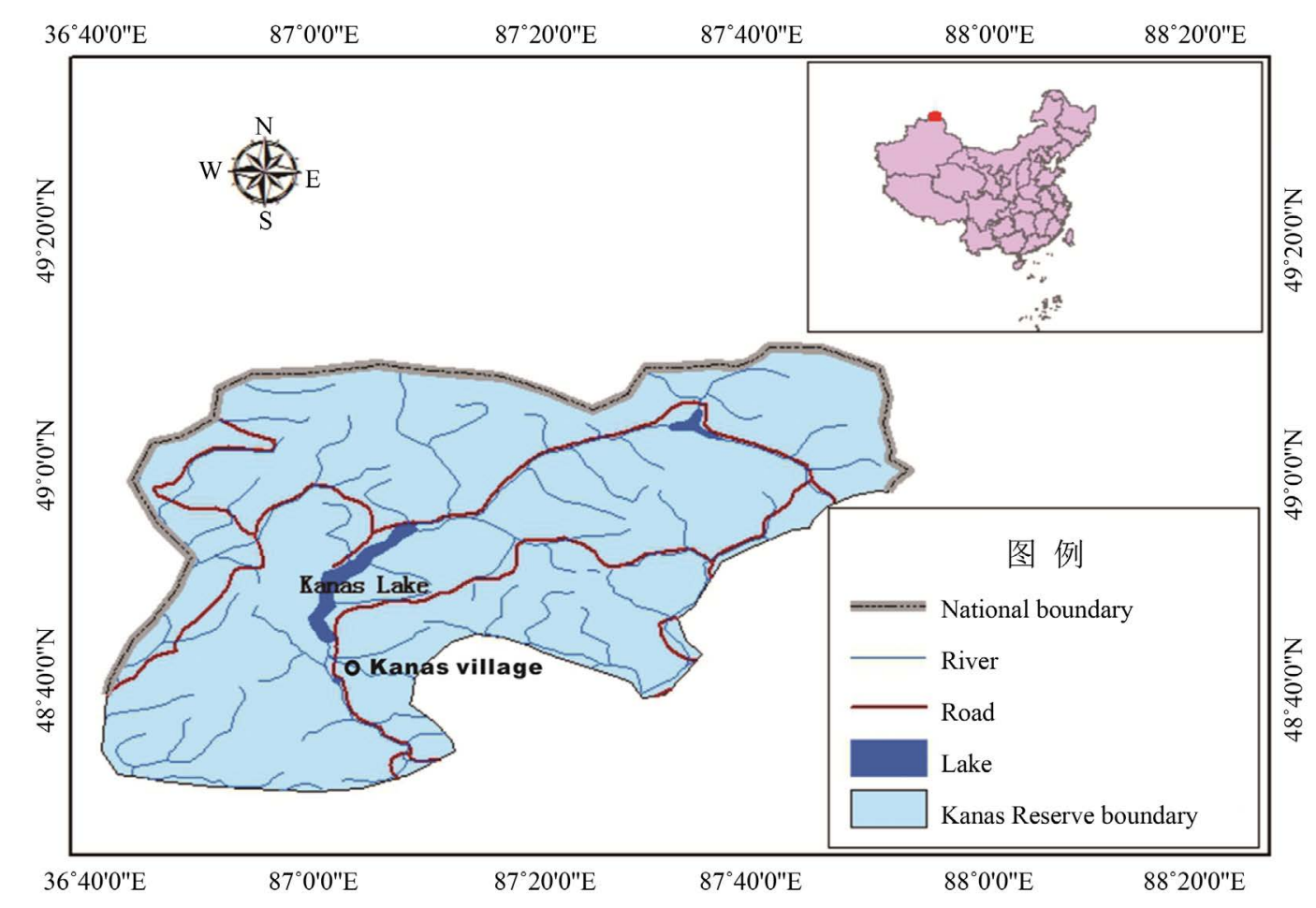

Figure 1. Location map of Kanas National Nature Reserve. 
Akekule Lake is located at the foot of the Mountain Friendship in the northeast of Kanas. It is $38 \mathrm{~km}$ from the white lake to the head of Kanas Lake and $60 \mathrm{~km}$ to the Hemu village. The path is treacherous and rarely visited by people from outside world. The altitude of the lake surface is $1954 \mathrm{~km}$ and its area is $9.5 \mathrm{~km}^{2}$. It is formed by glaciations.

2) River landscape. Kanas River is the major river in this zone. It flows through the whole zone from the northeast to the southwest. It's the largest branch of the downstream Burqin River, which is the largest branch of Irtysh River - the only river belonging to the Arctic Ocean water system. The Kanas River enjoys sound water quality and abundant hydropower. The major landscapes include riverside scenery, Wolong Bay, Moon Bay and Sanctuary Bay.

3) Mountain landscape. The Kanas Nature Reserve locates at the western part of Altay Mountain. The terrain slopes from the northeast to the southwest. It's hilly and very complicated with continuous snow mountains and ravines criss-cross. The altitude is between $1300 \mathrm{~km}$ and $4374 \mathrm{~km}$. The highest mountain is the Mountain Friendship in the northeast, at the top of which exist well preserved Quaternary glaciers.

4) Canyon landscape. The Kanas river canyon with turbulence, high mountains and deep valleys, forests and landforms provides a mysterious, tranquil and spectacular view.

5) Rare plant and fungus. The rare tree species in this area is the Siberian pine. There are more than 540 higher class plants. Because the moist soil and humid air are fit for the spread and grow of different kinds of fungus, there are various kinds of fungus and this type of resource is quite rich, most of which are great to eat and materials for medicine.

6) Wild animals. The complete natural and ecological system in Kanas has created a sound environment for the survival of the wild animals and an ideal place for their rest and reproduction. The animals known include 39 kinds of beasts, 4 kinds of reptiles, 117 kinds of birds and 10 kinds of fish. Among them, snow leopard, sable, glutton, goat and black stork are the first-grade national protection animals. The second-grade national protection animals include snow hare, brown bear, otter, lynx, rabbit manul, red deer, original musk deer, bonasa, goshawk, snow pigeon, rock ptarmigan, pana altaica, viviparous lizard, vipera berus and common grouse.

7) Forest landscap. Kanas Nature Reserve is the only distribution area of European/Siberian flora and fauna in China. It mainly consists of Siberian mountain conifers. The advantageous tree is unique in Siberia and basically stays at its original state. The nearly mature and over mature area and storage volume all exceed $97 \%$. The forest coverage rate is $19.4 \%$ and the rate reaches $82 \%$ in forest land. This area has the most kinds of plants in temperate grassland and has the only Taiga landscape, thus it is of great value for protection and scientific research.

8) Ice and snow landscape. Because of the impact of the Quaternary glaciers and the arctic climate, the Altai Mountain within this zone is one of the major distribution areas of contemporary glaciers. The area and reserve of glaciers in Kanas Nature Reserve account to $71.46 \%$ and $70.08 \%$ respectively of the total of Altai Mountain area. Looking into the distance at the side of Kanas Lake, one can see very clearly the magnificent ice and snow world at the Peak of Altai Mountain. Especially the Mountain Friendship with snow and glaciers is quite a grand vision. The quaternary glaciers here are well preserved and the glacial landforms are in full growth.

9) Meadow landscape. There is a fascinating meadow landscape with lush herbage and blooming flowers, which offers a perfect natural pasture. We can see different scenery at different altitude. The alpine meadow mainly locates between $2500 \mathrm{~m}$ and $3200 \mathrm{~m}$, subalpine meadow between $1800 \mathrm{~m}$ and $2400 \mathrm{~m}$, mountain brown coniferous forest between $130 \mathrm{~m}$ and $2300 \mathrm{~m}$ and cyperaceae between $1300 \mathrm{~m}$ and $1500 \mathrm{~m}$.

10) Clinate land scape. Kanas Nature Reserve is situated at the highest part of the Altai Mountain. The special climatic conditions, the location in the hinterland of the Eurasian continent, far from the sea, the high latitude, distinct altitude difference and complicated terrain result in the divergence in climate compared with neighboring regions and the obvious vertical zoning and horizontal zoning. This leads to the staggered distribution of vegetation vertical band and the forest and pasture on the Yin and Yang slopes, which is a typical representative of the cold temperate climate.

11) Folk custom. Kanas is the only habitation of the Tuvans. They were called dubo people in Sui and Tang dynasty and tuba people in Yuan dynasty. They speak Turki, which is similar to Kazakh. They live on hunting and grazing. In the last 400 years, they have settled down here and left historic and cultural relics including abundant cliff carvings and paintings. They have also maintained the ancient tribal concepts and religious beliefs. The Tuvans build their houses with wood and live on hunting. They are good at archery, horse riding and skiing. They are industrious, simple, brave and strong. Every year they will perform some religious activities such as 
sacrificing to heaven, to lake, to mountain, to fish and to fire. The Aoba Festival is the most important festival for them.

The Kazak is a nomadic nationality and they migrate to wherever water and grass are available. Therefore, they are also called the people on the horseback. The Kazak people are hospitable and good at singing, dancing and horse riding. Their traditional ethnic activities include buzkashi, horse racing and girls chasing. The major festivals are Kurban Festival and Roza Festival. The Aken Concert is a civil activity with the largest scale.

12) Scenery of the four seasons. Spring in Kanas is blazing with color and the mountain flowers are in full bloom. All kinds of wild flowers are blossoming, forming a sea of flowers. The white yurts, flocks of sheep and cloud clusters are radiating with the colorful grassland. In spring, the Kanas Lake is rippling with green waves and is as clear as crystal.

Summer in Kanas is so green as if the earth is covered with a green carpet without any stain. The smog is like holy white gauze floating and winding in the valleys. Take a breath you will find the air is so refreshing. Thanks to the white water from the white lake in the upper stream, Kanas Lake is dyed into milky white, which is a mysterious and spectacular view.

When it is autumn in Kanas we can see all the forests are dyed and the colorful hilltop has already begun to store snow. The original green slopes and forests turn into golden yellow, crimson and rosy. The whole wilderness is becoming increasingly attractive with autumn flavor.

Winter in Kanas is covered by snow. The perky land is almost sealed up by snow, presenting a sacred and silent atmosphere. The snow and fog hang on the pine branches quietly. Only the Tuvans' sleighs pulled by horses are still active on the vast snow land.

\subsection{Comment on the Eco-Tourism Zone}

1) The index of the regional ranks. The nature reserve is divided into 5 levels including world relics, national, provincial, regional and county level. According to the standard of the National Environment Protection Administration, Kanas Nature Reserve is a national level reserve, indicating a relatively high regional rank, especially under the special geographical conditions of Xinjiang where deserts take a large part.

2) Biological diversity. Biological diversity includes ecological diversity, diversity of species and genetic diversity. The visibility of biological diversity makes up the major characteristic of the Kanas eco-tourism zone. The complexity and good taste of the biodiversity are very attractive to tourists. Preliminary investigation has showed that there are over 1500 kinds of plants and animals, suggesting Kanas Nature Reserve is rich in species.

3) The specificity of the elements of the eco-system structure. The specificity can be divided into 5 levels including unusual in the world, rare in China, unique in the province, exceptional in the region and common. According to relevant materials, Kanas Nature Reserve is the only distribution area of European/Siberian flora and fauna and the only Taiga landscape. The obvious specificity demonstrates the good taste of the eco-tourism zone.

4) The primitiveness of the ecological environment. Primitiveness represents the extent of human's interference on the regional ecological environment. The more primitive the region is, the more attractive it is to the tourists. The level of primitiveness can be divided into primitive, relatively primitive, light interfered, damaged and not primitive. Researches reflect that Kanas Nature Reserve remains primitive and undeveloped, which is quite an attraction for the tourists.

5) The stability of the eco-system. The stability of the eco-system consists of the stability of the structure elements and the normality of the functioning. The stability can be divided into stable, relatively stable, ordinary, relatively bad and bad. Kanas Nature Reserve is situated at the west side of the Altai Mountain, where earthquakes are rarely seen and the ecological environment is quite stable. Although people once chopped down forests, the vegetation recovered soon thanks to the superior climatic conditions. The eco-system, as the mountain composite belt, is extremely stable.

6) The diversity and specificity of the scenic spots. The more sightseeing tourism resources and scenic spots within the region, the more valuable it is to travel here and the more attractive it is to the tourists. While among the numerous sightseeing tourism resources, the more the special tourism resources and the higher quality they possess, the more attractive they are. Kanas Nature Reserve is a major eco-tourism zone in our country, enjoying at least 12 types of characteristic tourism resources and scenic spots. It is thus clear that the scenic spots within the region have evident diversity and specificity. 


\subsection{Comment on the Eco-Tourism Zone}

Kanas Nature Reserve borders on Kazakhstan and Russia in the north. To the south, it is $170 \mathrm{~km}$ away from the gold city Altay, $210 \mathrm{~km}$ away from Burqin county, $80 \mathrm{~km}$ away from Habahe county, 120 km away from Beitun county, $140 \mathrm{~km}$ away from Fuhai county and $300 \mathrm{~km}$ from the oil city Karamay. There are high class roads connecting all of them. The Heiliutan airport in Burqin county was finished in 2007, providing convenience for other regions in Xinjiang and tourists from other provinces. Therefore, Kanas Nature Reserve enjoys sound location and market conditions.

To sum up, the tourism resources, regional comment results and location and market conditions of Kanas Nature Reserve have proved that it has high development value and sound prospect.

\section{The Development of the Eco-Tourism Resources}

\subsection{The Principles for Development}

The eco-tourism development in the nature reserve must be guided by the concepts of sustainable development and environment ecology. The following principles should be abided by:

- The principle of function division. All nature reserves should have function divisions. The development of eco-tourism must be carried within the scope of the function divisions. According to the distribution and characteristics of the tourism resources, the function divisions of Kanas Nature Reserve can be divided into core zone (only for scientific research), buffer zone (transitional zone for some eco-tourism projects such as teaching and sightseeing), pilot zone (peripheral zone operating eco-tourism under the precondition of protecting the nature).

- The principle of environment protection theme. Developing tourism in nature reserve should strengthen the theme of environment protection. From the setting of the tourism projects and the composition of the guide words to the selection of the building materials, we should follow the principle of adjusting measures to local conditions and advocate the protection of the nature. For example, we should promote ecological buildings and pollution-free materials and exhibit the use of chemical coating and paint. We should also make the most of solar power and wind power. People can appreciate natural scenery and experience balanced environment through travelling. Thus they can receive ecological and scientific education and are inspired to love nature and think about life.

- The principle of controlling the capacity. The ecological balance in the nature reserve depends on the influence of the human's method and intensity towards the environment and resources, as well as the nature's self cleaning capacity against this kind of influence. When the number of tourists reaches a level that the environment and resources are damaged and cannot recover by nature's force, this number is called the critical capacity of a certain scope. Before developing, constructing and operating the scenic spot, we should have a planning of the tourist capacity according to the characteristics of the tourism resources in order to control the number of tourists effectively.

- The principle of coordination and integration. Necessary facilities in the nature reserve must keep coordinated and integrated with the natural landscapes. We should adopt the methods of making things done with whatever available, using local materials, fitting to the scenery and situation and adjusting measures to local conditions. The layout of the buildings should be small in size, private and separated.

- The principle of non-urbanization. We should try to limit the facilities of accommodation, catering, transportation, communication and management and arrange them in the periphery zones. Namely, traveling within the region and living outside the region. Blindly improving the grade of the reception facilities must be strictly prohibited. We should ensure the non-urbanization of the nature reserve.

\subsection{The Activity Projects of Eco-Tourism}

As the eco-system of the eco-tourism zone is fragile, the setting of the eco-tourism projects should uphold the following principles: 1) causing least damage to the ecological environment; 2) enabling the tourists to participate in the experimental activities and easy to control and manage; and 3) returning to and understanding nature while strengthening the awareness to protect the environment [8]. According to the type, structure, distribution and location features of the tourism resources in Kanas Nature Reserve and taking into consideration of the principles above, the optional projects are as follows: 
1) Ecological sightseeing. Ecological sightseeing means that the tourists can integrate with the nature and have visual perception of the environment by walking or other simple tools. For instance, appreciate the scenery of the four seasons; admire precious plants and animals; enjoy meteorological views including snow, sunrise and glory of the Buddha; observe mountains and rivers. This category of projects is one of the most common in various eco-tourism zones and provides a complete feeling.

2) Drifting. Drifting is a relatively exciting eco-tourism activity when one floats downstream in rivers and trenches aided by certain tools such as rubber boat, bamboo raft and rubber life belt. Drifting includes professional and leisure drifting. Ecological drifting is often for leisure and less demanding for tourists' skills. With simple tools like raft and boat, it is not as exciting as professional drifting but it is less dangerous, so one can feel excited floating downstream in Kanas River.

3) Horse riding. Horse riding is a kind of eco-tourism activity which tourists ride domesticated horses or other livestock along a certain path and enjoy the scenery on the way. Generally, the horses are tamed for the tourists, thus they are not dangerous but can excite the tourists. Horse riding should be accompanied and guided by specially-assigned person and follow fixed line in order to reduce danger and the damage to the environment.

4) Grass skiing. Grass skiing is a fresh eco-tourism activity. It offers a brand new feeling to ski along the slope with certain tools. The grassland should have high quality and specialized slide way under the management of specialized personnel.

5) Snow skiing. Skiing is a popular activity in many mountainous tourist attractions. Skiing with tools on gentle slope in mountainous area covered by snow requires thick snow and paths fit for skiing. Tourists can participate in this activity after simple training.

6) Gliding. Gliding is an activity which the tourists glide in the sky from high place to lower place with certain tools. This is a high demanding activity thus participants need specialized training and guidance.

7) Cliff climbing. Cliff climbing means climbing on some steep and firm cliffs with certain tools. Cliff climbing calls for high security and the participants should be guided. This activity gives people a strong sense of achievement and is most attractive to young people.

8) Mountain cycling. Riding bicycle in mountainous area offers a stronger sense than on flat ground. So it's also attractive to ordinary tourists.

9) Camping. Camping is staying in the wild overnight within tents or other facilities. Surrounding the bonfire, putting on performances, listening to the nature's various sounds or talking to the nature are all charming activities for people who live in the city for a long time.

10) Scientific expedition. It has become a popular activity in recent years to explore creatures and geological sites in primitive environment. It can provide more direct knowledge. The expedition includes investigating the diversity of creatures, collecting specimen, inspecting geologic section, studying the origin of the Tuvans, exploring precious plants and animals and geographical expedition in the cold temperate zone.

11) Spending the holiday in the cabin. Spending the holiday in the cabin means living in the specially built cabin for a relatively long time in a good environment. The tourists can take forest bath, drink mountain spring and breathe fresh air as well as take part in a series of activities such as sightseeing and body-building. When building the cabin, we should make sure it is simple, clean and tidy. It should also have little impact on the environment.

12) Exploration. Exploration consists of exploring the caves, mountain climbing, drifting, exploring the glaciers, cliff climbing and discovering precious plants and animals. All these explorations are challenging and exciting.

13) Leisure agriculture. We should carry out popularity education on ecological agriculture. The tourists can visit ecological orchard and sample ecological agriculture zone. They also have the opportunity to appreciate flowers, taste fruits, visit the gardens, taste green food, relax and visit ecological folk habitat. Through participating in agricultural labor, they can also enjoy the pleasure and happiness of the countryside.

14) Mountain spring bath. Taking a bath in the clear mountain stream, lake, hot spring or pond not only offers a cool feeling but also makes one feel like returning to his original nature. With the development of hot springs, hot spring vocational tourist attractions emerge in some mountainous regions. As many hot springs have a role to play in people’s recuperation, these attractions are becoming increasingly popular.

\subsection{The Construction Projects of Eco-Tourism}

1) Visitors village. The village should be constructed at the flat and broad Tumu town, which is located at the 
entrance of the reserve and outside the pilot zone. The projects include interpretive center, environment protection education center, reception station, information agency, administrative office, shopping mall and ecological park. The interpretive center should offer multi-media exhibition and consulting service so as to introduce the natural resources and cultural value of the eco-tourism zone, code of conduct and security guideline of camping to the tourists. The village should keep harmony with surrounding environment. Tall buildings must be strictly prohibited.

2) Accommodation facilities. The construction of accommodation facilities should pay attention to the following points: a) they should be non-permanent facilities; b) it is not appropriate to pursue the grade of the facilities and the facilities should not have more than three floors; c) they should be consistent with the natural characteristics and ethnic customs; d) the number of bed needed should be predicted according to the demand of tourism; e) supporting drainage system should be built; f) green toilets should be constructed. The eco-tourism accommodation facilities are mainly cabins, youth hotels and tents.

3) Catering facilities. We should supply green restaurants and set up pubs, bars, cafés, buffet restaurants and tea houses. We should also provide green food, fuel, power supply, source of water, lighting, purchasing, catering and management. Supporting sewage treatment plants must be built to eliminate pollution sources.

4) Green shopping and entertainment facilities. Associated facilities should not be assigned in the eco-tourism zone. Precious plants and animals are banned to be used as materials of souvenirs. We should promote entertainment arena and activities projects advocating environment protection and ecological theme.

5) Denoter. We should set various kinds of pegs and scutcheons in the scenic spots and along the paths according to terrain and actual demand. The four kinds of denoters are perimeter pegs, boundary pegs, interpretive scutcheons and restrictive scutcheons. Thus the tourists can avoid getting lost or entering non-tourism zone and dangerous area.

6) Communication and security. Electricity and communication circuits as well as green rescue system should be constructed to ensure the smooth operation of eco-tourism.

\subsection{Industrial Development of Eco-Tourism}

1) Sparing no efforts to popularize ecological sightseeing agriculture

We should carry demonstration experiments such as the introduction and domestication of precious plants and animals and other creatures, research on biodiversity, construction of natural products base and ecological reconstruction between buffer zone and periphery zone. We should utilize protection belt, woodland and hilly land to develop ecological orchard, sightseeing medical materials, ecological agriculture, sightseeing animal husbandry and scientific agriculture, thus the tourists can appreciate them and receive science education.

2) Striving to develop garden economy

The development of garden economy should be based on the peasant household and under the united training and guidance of the administrative department. They can carry out reception duty and run household hotels. They can establish bases for planting and raising pollution free Chinese medicine, growing characteristic fruits, cultivating high quality ornamental plants and nursery stocks, planting tea, growing and processing wild vegetables. These will help to drive the planting and breeding work of the farmers and increase their income.

\section{Countermeasure for the Sustainable Development of Eco-Tourism}

\subsection{Current Problems to Be Solved Immediately}

According to relevant regulations of the local government, Kanas eco-tourism development zone is generally divided into two parts. The scenic region management committee is in charge of the development, construction and management of this region, while the investors are responsible for the service, infrastructure, operation and management outside the scenic area. As the administrative department and investors lack eco-tourism concept and environment protection awareness, the management of the nature reserve is in a mess. It mainly shows in the following aspects:

1) Lacking government control and increasingly prominent anarchy

a) Tourism planning, development and construction disjoint from operation, even the situation of detailed planning before overall planning, development before planning, construction before development and operation before construction has emerged. Under the circumstance of developing and constructing without overall plan- 
ning, the scenic zone often suffers from overburden.

b) The development of the scenic zone, the construction of the projects and investment are in anarchy state. On one hand, the government doesn't play its dominant role in the region's planning, development, construction and management. On the other hand, the government doesn't do well in administrating the investors, examining the investment programs and controlling the number of investors and development projects.

c) The investors do business in their own way, conduct vicious competition and rush into mass action. Without analyzing the guest market and assessing the ecological capacity of the environment, they enhance the grade of the reception facilities blindly and increase beds arbitrarily.

d) Unauthorized constructions haven't been removed in time. They continue to exist with destructive development and illegal operation.

e) The general layout of the eco-tourism zone is unreasonable. For instance, there are no basic function divisions according to the requirement of the nature reserve. As the core of the nature reserve, there are flooding unauthorized constructions around Kanas Lake.

2) The damage of the tourism resources and the pollution of the ecological environment are becoming increasingly serious

a) Because of the impact of the above factors, the sustainable development of the Kanas National Nature Reserve is severely restricted. This mainly shows in the following aspects:

b) The damage of the tourism resources is becoming increasingly serious, which can be demonstrated by the following phenomenon: a large number of construction projects are going on in the core zone; stocks are used to build flats and pave roads; constructing high class cement roads in the scenic zone; damaging grassland and meadow; using wood as fuel; using gasoline and diesel to power pleasure boat; occupying forest arbitrarily; operating the scenic zone exceeding its capacity. The natural resources and environment in Kanas Nature Reserve are suffering severe damage because of human factors.

The pollution of the ecological environment is getting more grievous. This mainly shows in the following aspects:

- Tail gas from the vehicles entering the scenic area without permission, exhaust gas from the factories and mines outside the scenic area, smoke from burning coal by hotels, restaurants and households are all polluting the air in the scenic zone;

- The number of the unauthorized touring ship powered by gasoline and diesel exceeds normal level. Waste water from the hotels and domestic sewage are polluting the water resources in the scenic region.

- Solid wastes pollution from local residents and tourists.

- After the text edit has been completed, the paper is ready for the template. Duplicate the template file by using the Save As command, and use the naming convention prescribed by your journal for the name of your paper. In this newly created file, highlight all of the contents and import your prepared text file. You are now ready to style your paper.

\subsection{Strategic Resolution for Sustainable Development}

The following strategies are put forward to cope with the problems above:

1) Establishing a legislation system for the eco-tourism programming

Whether the eco-tourism programming is perfect is of profound significance for the eco-tourism and sustainable development of the Kanas Nature Reserve. First, we should formulate and perfect the basic law of tourism programming and direct it into the legalized track; second, we should explicit the legal nature of the behaviors related to tourism programming; third, we should resolve bull management in the process of tourism programming; fourth, we should establish and improve the comment system about the influence on the environment in tourism programming; fifth, improve the accreditation regime through setting up qualification system for the judges in order to ensure the scientific of tourism programming.

2) Establishing an eco-tourism environment protection planning system

Through this system we can have scientific assumption, design and prediction about the prospect of the eco-tourism development in Kanas Nature Reserve thus we can ensure its sustainable development [9] [10]. The following aspects deserve our attention: a) the matching development of eco-tourism environment protection industry and other related industries; b) the coordination and integration of the ecological environment system and social economic system; c) setting up a regime about the influence on the environment; d) dividing the 
eco-tourism zone according to its function and protecting it; e) attaching importance to the overall environment construction when developing eco-tourism

3) Establishing an eco-tourism environment protection auditing system

Eco-tourism environment protection auditing is a process in which we predict the organization and operation of the enterprises of the developers. This system helps us to find out whether the enterprises adhere to the designated regulations, standards and policies. Eco-tourism environment protection auditing system operates through environment influence assessment (ELA), environment influence statement (EIS) and environment management system (EMS). Environment protection auditing system emphasizes the following points: a) the developers should work out a systematic comment and scheme about the influence on natural resources, economic conditions, aesthetic appreciation, social environment and cultural field during the process of eco-tourism development; b) the developers must employ qualified professional institution to formulate a specified environment influence document which consists of the possibility, probability and inevitability evaluation about the influence on the environment as well as a resolution on the EMS's quality, scope and depth; c) the government should supervise and control the environmental protection, influence, detection and recovery of the developers involved projects.

4) Establishing an eco-tourism environment protection legislative and law enforcement system

The most serious problem the eco-tourism environment protection of Kanas Nature Reserve is faced with is lack of strict legislation and powerful law enforcement. In terms of legislation, we should strengthen our efforts in formulating administrative laws and regulations, departmental rules and local laws and regulations and improving various implementing regulations. Except for the environment protection departments, different levels of tourism management sections should set up specialized institutions to strengthen law enforcement efforts. We must have strict legislation, powerful law enforcement and punishment on those who break the law [11].

5) Establishing an eco-tourism ethical education and management system

We should set up a virtuous circle mechanism of the coordinated development between eco-tourism education and eco-tourism industry. The targets of education and training include administrative staff, investors, operators, tour guides, tourists and community residents.

\section{Acknowledgements}

The research was supported by Southwest Universities of Nationalities, with the project "academic degrees construction subject of College of History and Culture, project code 2012XWD-S1202”. The research was also financed by The Asian Development Bank with the project "Study on Suggestions and Implementation of Reconstruction of Urban and Transport Infrastructure in the Sichuan Earthquake-Stricken Areas”.

\section{References}

[1] Nabin, B. and Anal, D. (2014) Diversifying Finance Mechanisms for Protected Areas Capitalizing on Untapped Revenues. Forest Policy and Economics, 41, 60-67. http://dx.doi.org/10.1016/j.forpol.2014.01.002

[2] Tran, L. and Walter, P. (2014) Ecotourism, Gender and Development in Northern Vietnam. Annals of Tourism Research, 44, 116-130. http://dx.doi.org/10.1016/j.annals.2013.09.005

[3] Yin, K.P. and Yan, H.L. (2012) Eco-Tourism and Sustainable Development. Sichuan University Press, Chengdu.

[4] Chakrabarty, A. (2011) Ecotourism Development and Security Restructuring: A GI Based Planning for Peaceful Dissuasion of Anarchism in Forest Provinces of India. Procedia Social and Behavioral Sciences, 21, 108-115. http://dx.doi.org/10.1016/j.sbspro.2011.07.006

[5] Qin, J.X. (2003) Humble Opinion about Sustainable Development of the Tourism Industry in Chengdu City. China Sustainable Development, 10, 10-20. http://sd.thnet.gov.cn/zgkcxfzzz/

[6] Qin, D.H. (1999) China’s Population Source Environment and Sustainable Development. Xinhua Press, Beijing.

[7] Li, J.Q. (2001) Discussion on the Eco-Tourism Development of Labagou Nature Reserve in Beijing. China's Sustainable Development, 10, 10-20. http://sd.thnet.gov.cn/zgkcxfzzz/

[8] Yoder, A. and Bowler, P.A. (1998) Sustainable Development, Ecotourism, and Globalization: Are They Compatible? Interdisciplinary Minor in Global Sustainability. University of California, Irvine.

[9] Cleveland, C. (1999) Sustainable Tourism, Globalization, Regionalization and Third World Development. Regional Studie, 343, 34-56.

[10] Milton (1999) Sustainable Tourism: A Local Authority Perspective. Proceedings of the 7th Tourism and Sustainable 
Development commission, New York, 19-30 April 1999, 19-30.

[11] Pearce, D. (2001) Cultural Tourism and Sustainable Development in the Arab Region. Journal of Environment Management, 45, 1-10. http://link.springer.com/search?query 
Scientific Research Publishing (SCIRP) is one of the largest Open Access journal publishers. It is currently publishing more than 200 open access, online, peer-reviewed journals covering a wide range of academic disciplines. SCIRP serves the worldwide academic communities and contributes to the progress and application of science with its publication.

Other selected journals from SCIRP are listed as below. Submit your manuscript to us via either submit@scirp.org or Online Submission Portal.
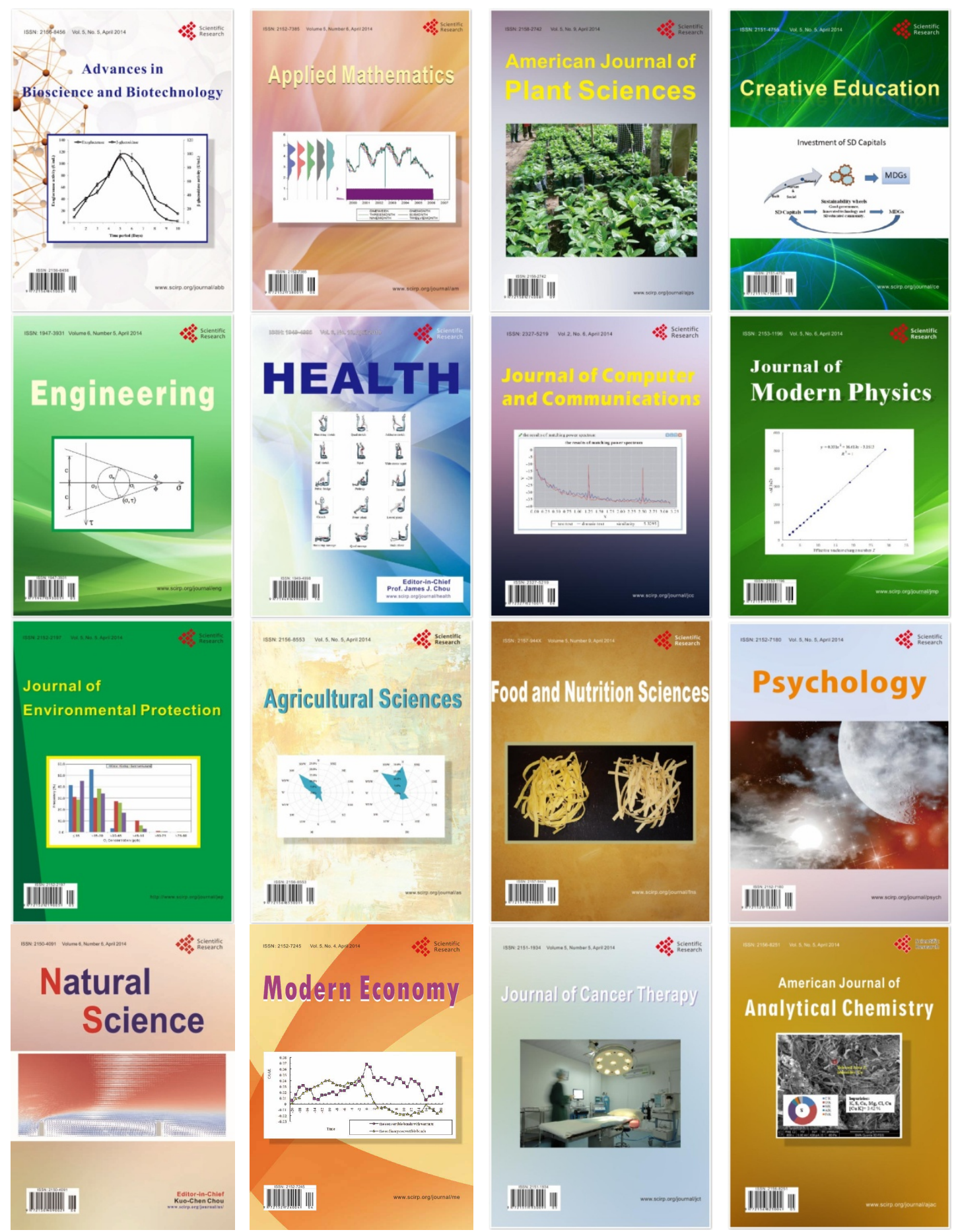